\title{
Application of Mycobacterial Peptide as Recombinant Antigen for Diagnosis of Bovine Tubercullosis
}

\section{Wagdy Samir ${ }^{1}$, Kamilia Mahmoud Osman ${ }^{2 *}$, Emad Mokhtar Riad ${ }^{1}$, Ashraf Hakim ${ }^{3}$}

${ }^{1}$ TB Unit, Animal Health Research Institute, Dokki, Giza; ${ }^{2}$ Department of Microbiology, Faculty of Veterinary Medicine, Cairo University; ${ }^{3}$ Department of Microbiology and Immunology, National Research Centre, 33 Bohouth St., Dokki, Cairo, Egypt.

\begin{abstract}
Mycobacterium bovis is acid fast bacterium causes bovine tuberculosis; a serious chronic infectious disease which not only affects cattle, but other tamed species and wild animals. The disease of public health importance as it transmits to humans. $M$. bovis-infected cattle foremost trigger a cell-mediated immune response and therefore, for numerous years control programs depend on the skin testing with the Bovine-purified protein derivative (b-PPD). Otherwise, the tuberculin skin test (TST) has many limitations, and many drawbacks, so the aim of our study was focus on the needing to identify other specific antigens of $M$. bovis which are absent in BCG and nearly most non tuberculous species for achieving more accurate specificity and higher sensitivity. One of these antigens; ESAT-6, which was prepared from well identified of $M$. bovis strains which used in both serum dependent tests as ELISA and whole blood techniques; IFN- $\gamma$ assay as a diagnostic test for tuberculosis. as well as used in skin testing in parallel to tuberculin test. So, we successfully cloned and expressed the r-ESAT- 6 antigen in pure form and identified by SDS page and immunoblotting technique. It is used in skin testing in infected guinea pigs with by killed $M$. bovis and it showed clear response using different used doses of prepared antigen as well as it was used in ELISA on 500 serum samples from tuberculin tested animals and in Gamma interferon assay on 50 tuberculin tested animals. The obtained results proved the antigenicity and immunogenicity of the prepared antigen as it can detect seven cases tuberculous positive from tuberculin negative cases by ELISA and three cases by gamma interferon assay. The sensitivity and specificity of each used test were recorded and discussed. It was concluded that the purified ESAT- 6 was implementable as a specific and sensitive tool alternative to ordinary diagnostic procedures. It also declare that use of this antigen resulted in a marked improvement in the ELISA and IFN- $\gamma$ release among both TST negative and TST positive cattle.
\end{abstract}

Keywords $\mid$ M. bovis, ELISA, Gamma interferon, ESAT-6 antigen ESAT-6 antigen, Bovine tuberculosis

Received | June 03, 2021; Accepted | July 10, 2021; Published | September 25, 2021

*Correspondence | Kamilia Mahmoud Osman, Department of Microbiology, Faculty of Veterinary Medicine, Cairo University; Email: kamelia-osman@hotmail. com

Citation | Samir W, Osman KM, Riad EM, Hakim A (2021). Application of mycobacterial peptide as recombinant antigen for diagnosis of bovine tuberculosis. Adv. Anim. Vet. Sci. 9(11): 1765-1775.

DOI | http://dx.doi.org/10.17582/journal.aavs/2021/9.11.1765.1775

ISSN (Online) | 2307-8316; ISSN (Print) | 2309-3331

Copyright (C) 2021 Samir et al. This is an open access article distributed under the Creative Commons Attribution License, which permits unrestricted use, distribution, and reproduction in any medium, provided the original work is properly cited.

\section{INTRODUCTION}

$\mathrm{B}$ ovine tuberculosis (BTB) is a chronic infectious illness caused by an acid fact bacilli; Mycobacterium bovis (M. bovis), which not only infects cattle but also other domesticated and wild animals (Michel et al., 2011). This illness causes great negative economic impacts in livestock industry via condemnation of animal and animal products. Furthermore $M$. bovis threatens the public health as it can be transmitted to humans via contaminated milk and meat (Bennett and Cooke, 2006).

BTB is considered a worldwide major issue among cattle herds in several countries around the world and is now a major problem in many countries. In spite of its rate in developed countries is greatly minimized due to application of milk pasteurization (Hardie et al., 1992), the insistence of $M$. bovis still regards for up to $10 \%$ of the human cases 
suffered from tuberculosis in some countries (Cosivi et al., 1998).

In order to combat and control this illness; there are different programs vary from firm regulation of animals' import and export as well as extensive movement. Moreover, application of skin test combined with slaughter slaying policies, have significantly diminished the incidence of the illness. Nowadays, it is evident that more efficacious diagnostic techniques with boosted specificity for extirpation, and monitoring programs are demanded to control BTB (Picasso-Risso et al., 2021).

$M$. bovis-infected cattle foremost trigger a cell-mediated immune response and therefore, for numerous years control programs depend on the skin testing with the bovine purified protein derivative b-PPD (Dipankar et al., 2006).

Tuberculin skin test (TST) is founded on the increasing in skin thickness gauge 72 hours post the intradermal inoculation of PPD. The inflammatory reaction constitutes infiltration of antigen-triggered lymphocytes with release of inflammatory cytokines (Behr et al., 1999).

Regardless of the variability in sensitivity and specificity, TST has turned into a tool that aids in prevalence drooping and eradication of bovine tuberculosis in various countries. In the same time there are many drawbacks of skin testing; requirement of twice animals' immobilization (for the injection of PPD and for the readout). Moreover, TST is deficient in both objectivity and uncertainty as it cannot be repeated for 2 months due to desensitization. As a sequel, blood-based diagnostic techniques have been evolved which based on the ability of certain to stimulate the cellular release of cytokines, especially gamma interferon (IFN) (Wood et al., 1990; Whelan et al., 2011).

On the other hand, the humoral antibody-based responses to $M$. bovis are positively corresponded with the mycobacterial-triggered pathology and antigen load. Thence, serological assays may represent alternative methods for screening herds for $M$. bovis infection, consequently elevating the degree of detection of positive infected animals. Also, serological assays may have limited number of antigens implemented for the diagnosis of bovine tuberculosis (Whelan et al., 2011).

Antigens which used in enzyme-linked immunosorbent assay (ELISA) have been broadly evaluated and unfortunately the sensitivity and specificity of the assay still are relatively low. So, the investigations searching about new antigens for serological diagnosis of bovine tuberculosis is needed (Buddle et al.,1995; Amadori et al., 2002; Farias et al., 2012).
Some studies have clearly identified the early secretory antigenic target 6 (ESAT-6) as being the most overriding antigen used in immune assays that tested the infected cattle. The mycobacterial antigen ESAT-6 is a protein of low molecular weight which exists in the culture filtrate produced by virulent $M$. bovis. Worth noting, it is strongly achieved in infected cattle, and they do not educe a response in non- infected ones (Delogu et al., 2001).

In the present study, we have selected the recombinant ESAT-6 antigen to induce a cellular immune response as well as its diagnostic markers by using ELISA and the IFN- $\gamma$.

The target was to determine its diagnostic implementation in the field among cattle herds and the study was performed in both TST-positive animals as well as those from BTBfree areas in El-Sharkia governorate, Egypt.

\section{MATERIALS AND METHODS}

\section{BACTERIAL ISOLATES}

M. bovis used in this work were obtained from previous study (Osman et al., 2017), stock cultures were grown on Lowenstein-Jensen slants (Biolife ${ }^{\circledR}$ ) at $37^{\circ} \mathrm{C} / 4$ weeks, and transferred to Sauton liquid medium (Himedia, India) at $37^{\circ} \mathrm{C}$ for 4 weeks.

E. coli M15 was used as hybrid vector for gene expression and E. coli strain DH5a (Thermo Fisher Scientific, Waltham, MA, USA) was grown in standard liquid as LB (Miller) broth (Sigma) and solid media; LB (Miller) agar (Sigma).

\section{SAMPLES}

A total of 500 serum samples were collected from tuberculin positive reactors and were tested by ELISA using the prepared recombinant antigens as well as PPD. Furthermore, a total of 50 blood samples from tuberculin tested cows which were tested by gamma interferon assay using the prepared antigens in El-Sharkia governorate.

\section{Preparation of recombinant ESAT-6 antigen}

It was carried out according to (Farshadzadeh et al., 2010) as follow:

\section{PCR AMPLIFICATION}

DNA encoding ESAT-6 sequence is located in region of difference1 (RD1) and called EsxA or Rv3875 (Gene Bank accession number BX842584). The DNA fragment encoding ESAT-6 gene consisting of 288 nucleotides retried from NCBI gene bank. The Rv3875 gene from the M. bovis genome, which encodes the ESAT-6 protein, was used to design primers for PCR amplification of the gene. 
The sequences of the forward and the backward primers (Sigma) are as below:

ESAT6-F: ACGAGATCTACAGAGCAGTGGAATTTC (BgIII)

ESAT6-R: ACGGGATCCTGCGAACATCCCAGTGA (BamHI)

PCR was performed using standard conditions $\left(94^{\circ} \mathrm{C}\right.$ for $1 \mathrm{~min}, 58^{\circ} \mathrm{C}$ for $1 \mathrm{~min}$, and $72^{\circ} \mathrm{C}$ for $1 \mathrm{~min}, 35$ cycles). The $288 \mathrm{bp}$ PCR product was purified through Qiagen mini columns (GmbH, Hilden, Germany) as per manufacturer's instruction. Plasmid DNA was digested with BgIII and BamHI. Prior to ligation, the linearized plasmid DNA and insert DNA were gel purified using the QIAquick Gel extraction kit.

\section{GENE CLONING, EXPRESSION AND PROTEIN} PURIFICATION

Selected ESAT-6 gene was amplified by PCR and product was ligated into expressing plasmid vector pQE30 (Sigma) and recombinant pQE30-ES plasmid was constructed. This hybrid vector was transformed in E. coli M15 and expressed in optimal condition.

\section{CONSTRUCTION OF EXPRESSION VECTOR CONTAINING} ESAT-6 GENE

The ligation of ESAT-6 into pQE30 was performed using T4 DNA ligase (Sigma) and transformed into $E$. coli DH5 $\alpha$ cells. The plasmid pQE30-ES from the correct transformant was purified from an overnight culture of recombinant $E$. coli $\mathrm{DH} 5 \alpha$ cell and then transformed into the competent $E$. coli M15 cells and screened on LB (Miller) agar (Sigma) plates containing $50 \mu \mathrm{g} / \mathrm{ml}$ ampicillin and 30 $\mu \mathrm{g} / \mathrm{ml}$ kanamycin.

\section{EXPRESSION OF RECOMBINANT PLASMID PQE30-ES}

The transformed E. coli M15 cells harboring the pQE30-ES plasmid was used in the expression. Several transformants were cultured in $50 \mathrm{ml} \mathrm{LB}$ (Miller) agar (Sigma) supplemented with ampicillin $(50 \mu \mathrm{g} / \mathrm{ml})$ and kanamycin $(30 \mu \mathrm{g} / \mathrm{ml})$ at $37^{\circ} \mathrm{C}$. Protein expression was checked by electrophoresis in 15\% SDS-polyacrylamide gel and $5 \%$ stacking gel. The bacterial cells were centrifuged at $13,000 \mathrm{rpm}$ for $5 \mathrm{~min}$; the precipitate was re-suspended in $50 \mu \mathrm{l}$ of buffer as a sample-buffer, and boiled for $5 \mathrm{~min}$. The samples were clarified by centrifugation under the same conditions, and $10-\mu 1$ samples were placed onto the gel.

\section{Purification of Recombinant Antigens}

Recombinant ESAT-6 was purified by nickel-nitrilotri acetic acid (Ni2+-NTA) metal affinity chromatography according to the manufacturer's recommendations for purification of proteins under soluble conditions (Qiagene). After washing the column, recombinant proteins were eluted with $300 \mathrm{mM}$ imidazole. Purified protein was examined by SDS-PAGE gel electrophoresis followed by Coomassie brilliant blue staining of gel.

\section{SDS-PAGE ANALYSIS}

Total cell protein (TCP) was analyzed by SDS-PAGE using $15 \%$ polyacrylamide gel with a Mini Protean-III apparatus (Bio-Rad). The cell lysate was re-suspended in distilled water and denatured at $100 \mathrm{xC}$ for $5 \mathrm{~min}$ along with Lamelli buffer. Protein was electrophoresed on SDSPAGE using $15 \%$ polyacrylamide gel.

The protein gel was stained with $0.25 \%[\mathrm{w} / \mathrm{v}]$ Coomassie brilliant blue R-250 in 10\% acetic acid and 40\% methanol and destained with $10 \%$ acetic acid and $40 \%$ methanol (Laemmli, 1970).

\section{IMMUNOBLOTTING}

It was carried out according to Sambrook et al. (1992); proteins separated by SDS-PAGE were electroblotted to nitrocellulose membranes (Amersham Biosciences) and were blocked with 5\% non-fat milk in PBS containing $0.5 \%$ Tween 20 (PBST) for $1 \mathrm{hr}$. at room temperature (RT). The membranes were then washed with PBST for $10 \mathrm{~min}$.

The membranes then were incubated overnight at $4^{\circ} \mathrm{C}$ with sera diluted 1:500 in PBS. The blots were washed thoroughly with PBST as described above, and probed with horse radish peroxidase conjugated $\operatorname{IgG}$ (1:2000 dilution) (KPL, India) for $1 \mathrm{hr}$. at RT. The membrane was blocked by bovine serum albumin (BSA), and then dipped into commercial anti-ESAT-6 antibody (Abcam plc, UK).

\section{DTH SKIN TEST IN $M$. BOVIS-SENSITIZED GUINEA PIGS}

\section{ETHICAL APPROVAL}

Handling and inoculation of with animals followed the ethical guidelines of the Ethical Committee of the Cairo University, Egypt.

The test was carried out on a total of 45 Guinea pigs with average weight 250-300g according to (Elhay et al., 1998). Two groups of guinea pigs; one $(n=40)$ was sensitized with $M$. bovis by intramuscular inoculation of $0.5 \mathrm{~mL}$ of a sterile heat-killed suspension of $M$. bovis strain AN5. Other group of five non-sensitized guinea pigs was used to evaluate the specificity of the reagents. Thirty days after injection, the sensitized guinea pigs were used for testing PPD-B, ESAT-6 and phosphate buffer saline (PBS) as a negative control. The sensitized animals were prepared by clipping the hair from the entire abdominal and flank areas.

Different doses of prepared rESAT-6 protein were tested 
for their ability to produce delayed-type hypersensitivity (DTH) responses in guinea pigs sensitized with killed $M$. bovis. Sensitized guinea pigs were divided into 8 groups, and each group received a unique dose of rESAT- 6 . These doses included $(0.1 \mathrm{mg}, 0.2 \mathrm{mg}, 0.4 \mathrm{mg}, 0.6 \mathrm{mg}, 0.8 \mathrm{mg}$ and $1.0 \mathrm{mg}$ ) rESAT-6 protein, as well as $0.1 \mathrm{ml}$ PBS as a negative control and $0.1 \mathrm{ml}$ (5 IU) PPD as a positive control.

The induration diameter in guinea pig was read at $24 \mathrm{hrs}$. The data were expressed as means of diameters (in $\mathrm{mm}$ ) of induration standard deviations according to protocol used by the government.

\section{INDIRECT ELISA}

It was carried out according to (Hall and Thoen, 1985) as follow; a checkerboard titration method was performed to establish the optimal dilutions of antibodies, conjugate and the concentration of the coating antigen. Polystyrene 96-well microtiter plates (Thermofisher) were coated with $100 \mu \mathrm{l}$ of a $10 \mu \mathrm{g} / \mathrm{ml}$ concentration $(1 \mu \mathrm{g} /$ well) of (Bovine PPD, Prionics ${ }^{\mathrm{TM}}$ antigen and rESAT-6) in carbonatebicarbonate buffer $(\mathrm{pH} 9.6)$, at $4^{\circ} \mathrm{C}$ overnight.

The plates were washed three times with washing solution (KPL, Tech Solution, India).

After blocking the plates for $1 \mathrm{hr}$. at room temperature $\left(20^{\circ} \mathrm{C}\right)$ with $1 \%$ bovine serum albumin (BSA)/KPL, $\mathrm{pH}$ $8.0(100 \mu \mathrm{l} /$ well $)$, the plates were again washed three times; $100 \mu \mathrm{l}$ of a 1:100 dilution of serum in PBS was added to each of the wells and incubated for $1 \mathrm{hr}$ at RT.

The plates were again washed three times and incubated with $100 \mu \mathrm{l} /$ well of peroxidase-conjugated goat antibovine IgG antibody (KPL, India) diluted 1:1000 in PBS, for $1 \mathrm{hr}$.

Plates were washed as described above, and enzyme activity was assayed by incubation for $30 \mathrm{~min}$ in the dark at room temperature with $100 \mu \mathrm{l} /$ well of ABTS substrate (KPL, India). The reaction was stopped by the addition of $50 \mu \mathrm{l} /$ well of $0.5 \mathrm{M} \mathrm{H}_{2} \mathrm{SO}_{4}$, and the optical density (OD) was measured at $405 \mathrm{~nm}$ using an automatic microtiter plate reader (BIOTEK ELx800, USA).

\section{GAMMA INTERFERON ASSAY FOR THE DETECTION OF}

M. BOVIS IN THE BLOOD OF TESTED CATTLE

It was carried out according to (Wood and Rothel, 1994; Doherty et al., 2002) using the kit of (Prionics BOVIGAM $^{\circledR}$ Mycobacterium bovis Gamma Interferon Test Kit for cattle).

The test was applied on the whole blood samples of tested animals (50 samples).

The test was standardized and verified as the instruction of the kit.

Whole blood samples were taken before the skin test from all the tested cows and were stimulated with either avian PPD $(10 \mu \mathrm{g} / \mathrm{ml})$, bovine PPD $(10 \mu \mathrm{g} / \mathrm{ml}), 4 \mu \mathrm{g} / \mathrm{ml}$ for the prepared antigen ESAT-6/ $(1 \mu \mathrm{g} / \mathrm{ml})$.

Levels of IFN- $\gamma$ in culture supernatants were measured using the commercial available Bovigam enzyme-linked immunosorbent assay (Prionics, Schlieren-Zurich, Switzerland).

Cut-off value [Mean+3SD] was calculated from TB free animals and accordingly TB status was deemed positive when the SI of the samples was greater than the cut-off.

The reaction was read within 5 min. using a $450 \mathrm{~nm}$ filter with a $620-650 \mathrm{~nm}$ reference filter. The absorbance values will then be used to calculate data.

The interpretation results of Gamma interferon assay for detection of bovine tuberculosis according to the following equation (Wood and Rothel, 1994):

Positive $=$ OD bovine PPD - nil antigen $\geq 0.1$; and OD bovine PPD- avian $\geq 0.1$

Negative $=$ OD bovine PPD - nil antigen $\leq 0.1$; and OD bovine PPD- avian $\leq 0.1$

\section{RESULTS AND DISCUSSION}

\section{AmplificATION OF GENE ENCODING ESAT-6}

A single band of $288 \mathrm{bp}$ was successfully amplified from $M$. bovis genome represented the gene encoding ESAT-6 protein (Figure 1).

\section{CONSTRUCTION OF THE EXPRESSION VECTOR; PQE30- ES}

In our work, ESAT-6 gene was inserted into the prokaryotic vector $\mathrm{pQE} 30$, the clones were screened firstly using a set of restriction enzymes (REs); BgIII and BamHI. Figure 2 revealed two bands; one approximately 350 bps represented the ESAT- 6 gene combined with a part of the pQE30 backbone and the other of $4.12 \mathrm{kbp}$ represented the remaining backbone of $\mathrm{pQE} 30$ vector.

The structural gene encoding ESAT-6 was isolated and identified through DNA sequencing and showed a polypeptide of 95 amino acids. A high degree of matching between the recombinant ESAT- 6 gene and the gene bank data base was observed. 


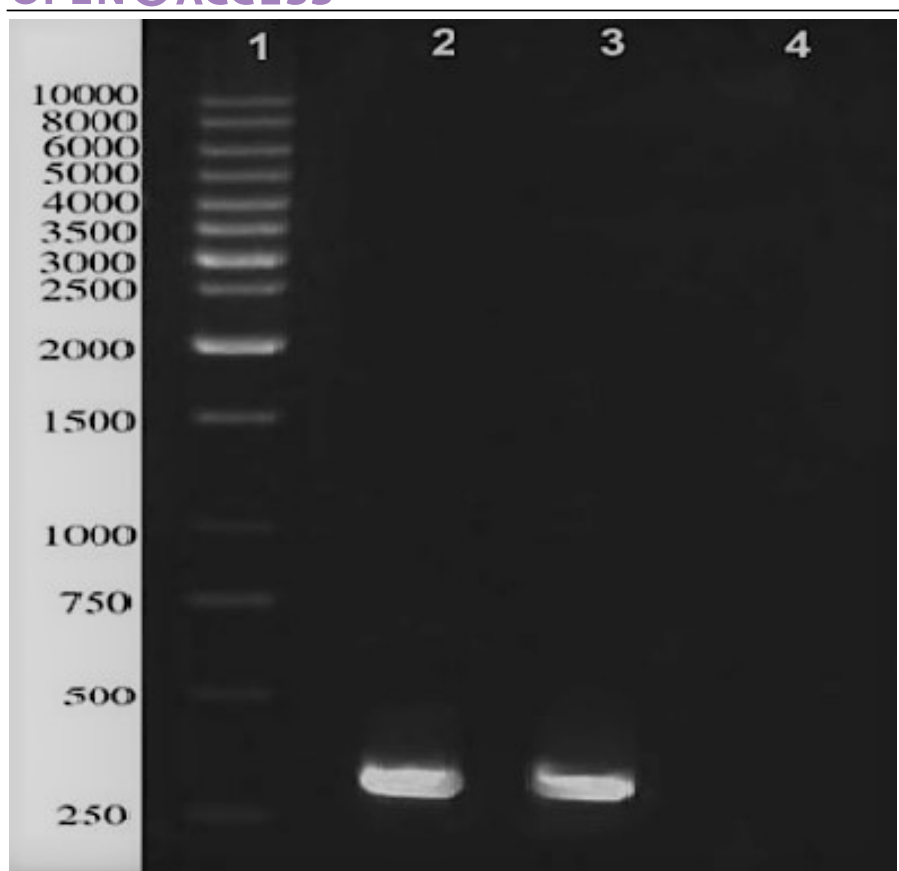

Figure 1: PCR amplification of ESAT-6 gene located in $M$. bovis genome; lane 1: $1 \mathrm{~kb}$ DNA ladder, lane 2 and 3 represent a distinct band in approximately 290 bps, Lane 4 is negative control.

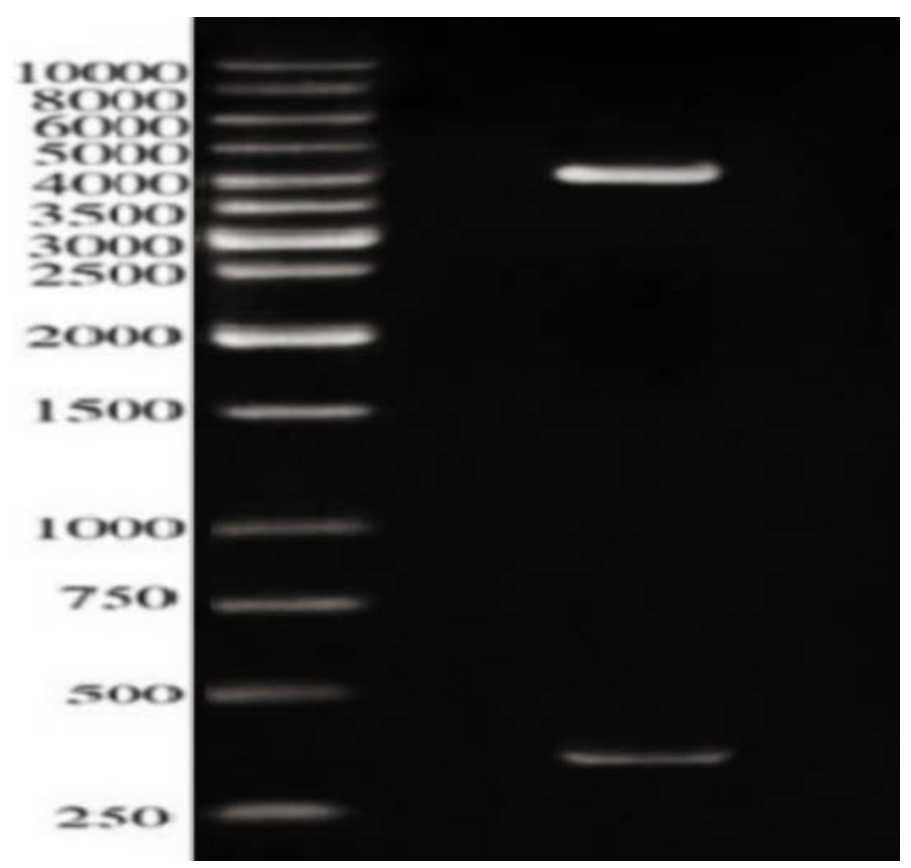

Figure 2: Restriction analysis of recombinant plasmid pQE30-ES against 10kbpDNA ladder; The Lower band is approximately $350 \mathrm{bps}$ while the upper band is about $4000 \mathrm{~b}$.

EXPRESSION OF THE PROTEIN ESAT-6

The inserted fragment was highly expressed from the hybrid gene using the His-tag cloning system.

The 15\% SDS-PAGE electrophoresis showed a band of molecular weight around $14 \mathrm{kDa}$ which represented the recombinant protein ESAT-6-(His) 6 (Figure 3). Notably, this obtained distinct band was not observed in negative control samples.

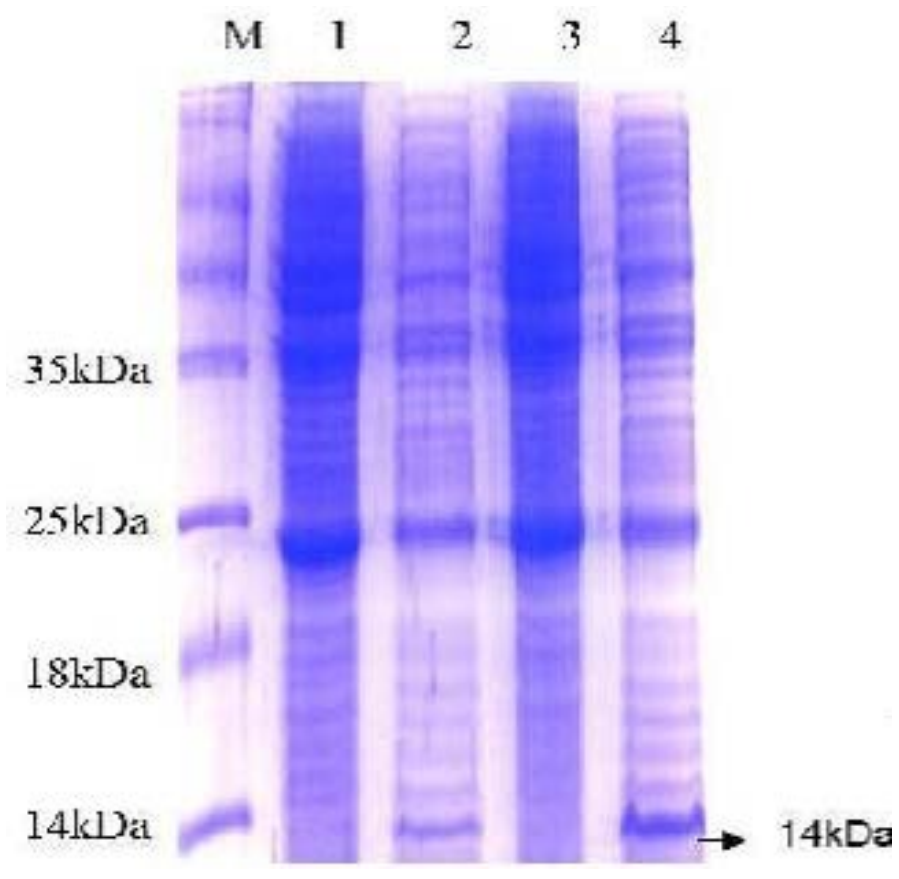

Figure 3: SDS-PAGE analysis of E. coli expressing ESAT6. Lane $\mathrm{M}$ : protein molecular weight standard marker, the arrow pointed to the target protein bands which were visualized by Coomassie blue staining.

\section{$\begin{array}{lllll}M & 1 & 2 & 3 & 4\end{array}$}

$35 \mathrm{kDa}$

$26 \mathrm{kDa}$

$19 \mathrm{kDa}$

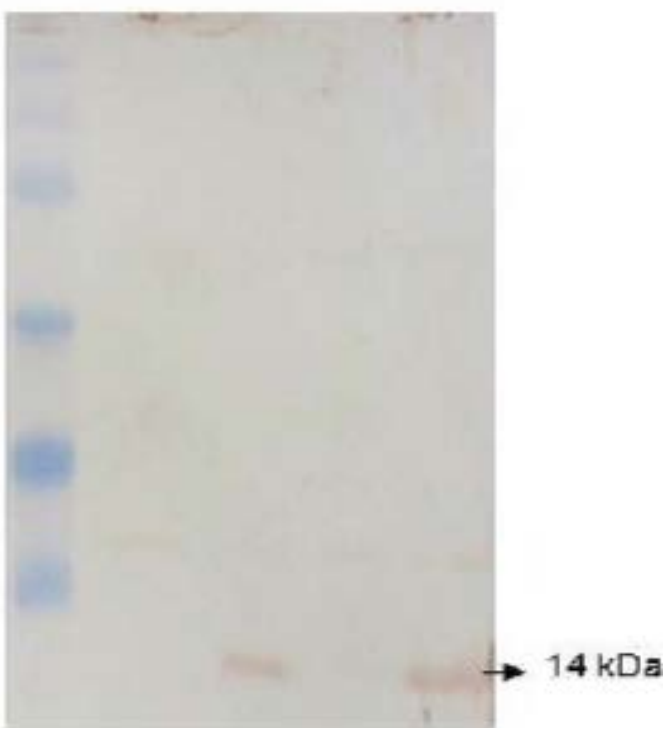

Figure 4: Western blot analysis of E. coli expressing ESAT6. Lane M: protein molecular weight standard marker, the arrow pointed to the developed blot indicated the presence of target protein.

Western blotting was carried out to assert the expression of the cloned protein by probing immunoblot immersed in the commercial anti-ESAT- 6 antibody and a developed blot of $14 \mathrm{kDa}$ was observed (Figure 4). On the other hand, the data of delay-type hypersensitivity reactivity 
to rESAT6 in guinea pigs sensitized with killed MTB revealed that all six rESAT- 6 doses tested induced positive DTH responses at 24 and 48 hrs after injection, which defined as an indurated thickness greater than $5 \mathrm{~mm}$ in diameter (Table 1).

Table 1: Skin reactivity to different doses of prepared recombinant antigens in guinea pigs sensitized with killed Mycobacterium bovis.

\begin{tabular}{|c|c|c|c|}
\hline \multirow[t]{2}{*}{ Groups } & \multirow[t]{2}{*}{ Doses } & \multicolumn{2}{|c|}{$\begin{array}{l}\text { Skin reaction in guinea pigs sensitized } \\
\text { infected by dead } M \text {. bovis (mean SD } \\
\text { represented as } \mathrm{mm} \text { in diameter) }\end{array}$} \\
\hline & & $24 \mathrm{hrs}$. & $48 \mathrm{hrs}$ \\
\hline PBS & 0.1 & 0 & 0 \\
\hline PPD & $5 \mathrm{IU}$ & 8.19 & 7.4 \\
\hline \multirow{6}{*}{$\begin{array}{l}\text { rESAT-6 } \\
\text { antigen }\end{array}$} & $0.1 \mathrm{mg}$ & 5.6 & 5.1 \\
\hline & $0.2 \mathrm{mg}$ & 6.2 & 5.6 \\
\hline & $0.4 \mathrm{mg}$ & 8.31 & 7.1 \\
\hline & $0.6 \mathrm{mg}$ & 9.3 & 7.37 \\
\hline & $0.8 \mathrm{mg}$ & 9.29 & 7.57 \\
\hline & $1 \mathrm{mg}$ & 9.61 & 8 \\
\hline
\end{tabular}

PBS indicates (phosphate-buffered saline); PPD indicates (purified protein derivative) while SD indicates (standard deviation).

\section{INDIRECT ELISA}

The indirect ELISA was carried out to evaluate the immunogenicity of prepared antigen in comparison with PPD and commercial polypeptide antigen of prionics $^{\mathrm{TM}}$ with regards to the results of tuberculin test. The results of ELISA showed that, out of 500 tested animals 42 cases were tuberculin positive with a percentage of $8.4 \%$, while the same tested animals revealed 43 positive cases (8.6 \%) by ELISA using PPD antigen and 47 positive cases $(9.4 \%)$ using commercial antigen, on the other hand the use of prepared antigen (rESAT-6) revealed 49 positive cases (9.8\%), as shown in (Table 2). All positive cases were examined for detection of the sensitivity and specificity of each used antigen, as shown in (Table 3).

IN VITRO DIAGNOSIS OF BOVINE TUBERCULOSIS BY GAMMA-INTERFERON ASSAY

Gamma interferon assay applied on whole blood collected from 50 animals submitted to the single intradermal cervical tuberculin test (SICTT) using the PPD-B and the prepared rESAT- 6 antigen. IGRAs and TST was performed in animals from the private farms at El-Sharkia governorate. The results showed that 28 animals were positive with percentage (56\%) with prepared antigen, while the results of tuberculin test of same animals revealed a number of 24 reactors (48\%), as shown in Table 4. All positive cases were examined for detection of the sensitivity and specificity of each used antigen, as shown in Table 5.

Table 2: the results of the tuberculin test, ELISA using prepared antigens, commercial antigen and PPD. of 500 tested cows.

\begin{tabular}{|llllllllll}
$\begin{array}{l}\text { Number Tubercu- } \\
\text { of tested lin test } \\
\text { animals }\end{array}$ & \multicolumn{4}{c}{$\begin{array}{c}\text { ELISA } \\
\text { Commercial } \\
\text { antigen }\end{array}$} & PPD & \multicolumn{2}{c}{$\begin{array}{c}\text { rESAT-6 } \\
\text { antigen }\end{array}$} \\
\hline 500 & No. & $\%$ & No & $\%$ & N & $\%$ & N & $\%$ \\
\hline & 42 & 8.4 & 47 & 9.4 & 43 & 8.6 & 49 & 9.8
\end{tabular}

Bovine tuberculosis (BTB) is a chronic infectious disease caused by $M$. bovis, which affects cattle, other domesticated species, wild animals and humans (Michel et al., 2011). This disease causes economic losses in livestock farming and poses a health risk to the population that consumes products of animal origin (Bennett and Cooke, 2006). BTB has been spreading in cattle herds in several countries around the world and is now a major problem in many countries.

Despite all the efforts to control BTB, this disease causes a significant economic burden to the agricultural industries and for human health. Eradication programs by tuberculin testing and slaughter of positive animals have been successful in many countries. However, a tuberculin test is limited in its specificity and sensitivity and bacterial culture is long (Aghazadeh et al., 2016).

Hence, production of synthetic peptides can help us for rapid differential diagnosis of pathogenic and nonpathogenic Mycobacteria and increasing the sensitivities and specificities of the serological assays in suspected BTB as a diagnostic tool in control TB.

Table 3: Sensitivity and specificity of ELISA in cattle recruited in this study, $\mathrm{n}=500$.

$\begin{array}{lllllll}\text { Method of diagnosis } & \text { Positive } & \text { False negative } & \text { Negative } & \text { False positive } & \text { Sensitivty } & \text { Specificity } \\ \text { Tuberculin test } & 42(8.4 \%) & 10 & 458(91.6 \%) & 6 & 80.8 & 98.1 \\ \text { ELISA Commercial antigen } & 47(9.4 \%) & 2 & 453(90.6 \%) & 3 & 95.9 & 98.1 \\ \text { ELISA PPD } & 43(8.6 \%) & 8 & 457(91.4 \%) & 5 & 84.3 & 98.1 \\ \text { ELISA rESAT-6 antigen } & 49(9.8 \%) & 3 & 451(90.2 \%) & 2 & 94.2 & 98.9 \\ \text { RT-PCR } & 51(10.2 \%) & & 449(89.8 \%) & & \end{array}$


Table 4: Results of in-vitro whole blood gamma-interferon assay:

\begin{tabular}{lllllll}
$\begin{array}{l}\text { Number } \\
\text { of tested } \\
\text { samples }\end{array}$ & IFN- $\gamma$ & & & & \multicolumn{2}{l}{$\begin{array}{l}\text { Tuberculin } \\
\text { test }\end{array}$} \\
& rESAT-6 & & PPD-B & & & \\
& Positive & & Positive & & & \\
& Number & $\%$ & Number & $\%$ & Number & $\%$ \\
50 & 28 & 56 & 25 & 50 & 24 & 48
\end{tabular}

Previous researches declared that ESAT-6 is a secretory protein encoded by gene located in $\mathrm{RD} 1$ in the genome of different virulent Mycobacteria species and is specifically not exist in either BCG vaccine strains or in $90 \%$ of environmental Mycobacteria (Berthet et al., 1998; Buddle et al., 2002; Okkels et al., 2004). ESAT-6 produced as scarce amount in the culture medium and has become a significant subject for researches because of its prominent role in the pathogenesis and immunogenicity processes occurred in $M$. bovis infections. This antigen has been elucidated recently to be one of the prime targets for memory effector cells within the memory immunity rendering in a mouse model of tuberculosis (Skjot et al., 2000; Brodin et al., 2004).

Wang et al. (2005) illustrated that the availability of adequate quantities of ESAT-6 antigen from $M$. bovis strains is a substantial step for studying its biological and immunological characters. Regrettably the slow growth of $M$. bovis hinders the obtaining of enough ESAT-6 amounts, so the recombinant production of this antigen was highly recommended.

In the current study, the amplification of ESAT- 6 gene was successfully performed from $M$. bovis $\mathrm{H} 37 \mathrm{Rv}$ genome DNA via PCR. The structural gene encoding ESAT-6 was isolated and identified through DNA sequencing and showed a polypeptide of 95 amino acids. A high degree of matching between the recombinant ESAT- 6 gene and the gene bank data base was observed. After that, the obtained fragment was introduced to $\mathrm{pQE} 30$; an expression vector and finally recombinant ESAT-6 protein was highly expressed from the hybrid.

Our investigation manifested that recombinant ESAT6, can be successfully expressed in prokaryotes; E. coli M15. This was emphasized via western blot analysis using specific monoclonal antibody against ESAT-6. This finding was coincided with various investigations that assess the application of ESAT- 6 as either a sole-component vaccine or as a constituent of a multiple-component vaccine in combination with the convenient adjuvant (Xu et al.,2006; Nosareva et al., 2008).

Notably, Van-Lume et al. (2008) stated that cloned gene or recombinant antigen could be of diagnostic value as well as the classical purified protein derivative.

In this study, a rESAT6 protein is purified and characterized as $14 \mathrm{kDa}$. This result was higher than that reported in another investigation which to be defined as $9.262 \mathrm{kDa}$ via SDS-PAGE and $11.119 \mathrm{kDa}$ via mass spectrometry as naive ESAT-6 (Aghazadeh et al., 2016). It was usual that the recombinant protein become higher than the naive one due to the existence of the tag on the cloned protein (Lauzi et al., 2000; Wang et al., 2005).

Our results revealed that the recombinant rESAT6 protein was greatly identical to the naive ESAT- 6 protein via the similarity amino acid residues $3-15$. On the other hand, by designing the first and second amino acid residues (Ala and Ser) in rESAT- 6 protein were differed from the naive protein, to maximize expression of the cloned protein. The same findings were reported by (Brodin et al., 2004).

Good to mention, our findings in guinea pigs illustrated that rESAT6 antigen has great potency as a skin test reagent (Table 1). We observed that inoculation of 1.0 $\mathrm{mg}$ of purified $\mathrm{rESAT} 6$ antigen induced similar reaction intensity detected in the skin test related to the PPD antigens, without any side effects in tested animals. The maximum response in the guinea pig model was observed between 24 and $48 \mathrm{~h}$ after antigen inoculation and showed higher sensitivity. These findings were harmonized with some previous studies which used ESAT- 6 protein as a skin test antigen in guinea pigs infected with TB (Arend et al., 2002; Mukherjee, 2006).

It is known that ESAT-6 is expressed fundamentally during not only in bacterial proliferation but also in nonproliferation. Not just like that it is expressed at levels 60-360 times higher than other genes during the nonproliferation phase. This phenomenon may have sole explanation that genetic variability plays a role in the ability of various animal species to respond against ESAT6 (Pollock et al., 2000).

It is always known that serological diagnosis of tuberculosis remains a challenge. For many years ELISA has been practically applied as a sensitive method for the measurement of antibodies in the sera of tuberculosis animals (Engvall and Perlmann, 1972). ELISA appears to be the best choice among serological tests and can be used for the confirmation of skin test results (Lightbody et al., 1998). Antibody-based assays may favor the detection of false negative reactors in the initial or advanced phases of the disease and so furnish more efficient eradication of the given disease (Whelan et al., 2008). To some extent there was focus on using of ESAT-6 recombinant proteins for sero-diagnosis of TB infection, (Moradi et al., 2015). 
Table 5: Sensitivity and specificity of IFN- $\gamma$ in cattle recruited in this study, $\mathrm{n}=50$.

$\begin{array}{lllllll}\text { Method of diagnosis } & \text { Positive } & \text { False negative } & \text { Negative } & \text { False positive } & \text { Senstivity } & \text { Specificity } \\ \text { Tuberculin test } & 24(48 \%) & 4 & 26(52 \%) & 2 & 85.7 \% & 92.9 \% \\ \text { IFN- } \gamma \text { PPD-B } & 25(50 \%) & 1 & 25(50 \%) & 2 & 96.2 \% & 92.6 \% \\ \text { IFN- } \gamma \text { rESAT-6 } & 28(56 \%) & 1 & 22(44 \%) & 1 & 96.6 \% & 95.7 \% \\ \text { RT-PCR } & 28(56 \%) & & 22(44 \%) & & & \end{array}$

In this study, it appeared from Table 2 that by ELISA using PPD as a coating antigen on cattle serum samples, $43(8.6 \%)$ animals were positive out of total 500 tested animals with $84.3 \%$ sensitivity and $98.1 \%$ specificity; while the data of ELISA using the commercial mixture antigen revealed that 47 animals were positive in a percentage of (9.4\%) with $95.9 \%$ sensitivity and $98.1 \%$ specificity. These results nearly agree with Desoky et al. (2015) who deduced that using the commercial antigen mixture ELISA appeared to be more effective and precise in diagnosis of bovine tuberculosis than when PPD was used. The obtained results of ELISA using rESAT- 6 as a coating antigen, demonstrated in Table 2 revealed that 49 (9.8\%) positive animals were recovered with $94.2 \%$ sensitivity and $98.9 \%$ specificity.

One of the main advantages of rESAT6 over PPD is the potential for greatly increased specificity. PPD contains many antigens common among different species of Mycobacteria and can therefore induce cross-reactions among animals and people with tuberculous infection, non-tuberculous mycobacterial infection and BCG vaccination.

Previous studies have also investigated the specificity of ESAT- 6 as a diagnostic antigen in animal models, and the results from these studies are consistent with what we have found (Melo et al., 2015; MohammadiTashakkori et al., 2018).

Recombinant ESAT-6 protein as skin test antigen cattle immunized with $M$. bovis but does not elicit any reaction in the guinea pigs immunized with BCG vaccine, on the other hand showed that the rESAT- 6 antigen elicited a skin test reaction in guinea pigs immunized with $M$. bovis, (Melo et al., 2015; MohammadiTashakkori et al., 2018).

However, some researchers focused on ESAT-6 recombinant proteins for sero-diagnosis of $\mathrm{TB}$ infection (Moradi et al., 2015).

In a study conducted with Aghazadeh et al. (2016) it has been demonstrated that ELISA with the use of the ESAT-6 antigens is simple and sensitive and can be used to analyze large numbers of samples for the serodiagnosis of BTB. In another study, the, ESAT-6/CFP10 recombinant proteins were used in the diagnosis and detection of TB by ELISPOT assays and showed sensitivity of $93 \%, 90 \%$, and $100 \%$, respectively. These data were significantly higher than the values obtained in conventional TST (Mostafavi-Pour et al., 2011; Waters et al., 2011) who proved that this antigen could be used for differential diagnosis of pathogenic and non-pathogenic Mycobacterium, in suspected BTB for development of ELISA diagnostic Kit (Pollock et al., 1997).

Comparing the results of tuberculin test, ELISA using different coating antigens and PCR as a standard method for diagnosis of bovine tuberculosis as shown in Table 3, it is declared that ELISA results using rESAT- 6 was of highest specificity and commercial mixture antigen of highest sensitivity. Our obtained data were supported by other studies (Melo et al., 2015; Mohammadi Tashakkori et al., 2018).

ESAT-6 is used currently as a stimulating antigen in the in vitro gamma interferon assay (Cellestis, Australia), and much work has been conducted with that product that confirms the sensitivity and specificity of this protein as a diagnostic agent (Wood et al., 1990).

The IFN $-\gamma$ release test is relatively fast and results can be analyzed within $30 \mathrm{~h}$ of collection of samples in comparison with the $72 \mathrm{~h}$ time required for TST and this method is superior with respect to its sensitivity as compared to TST. IFN- $\gamma$ can be used presently as a laboratory-based assay for TB diagnosis in cattle and further research has to be done before it can be used as a full-fledged field test and can provide results within one day (Pollock et al., 1997; Doherty et al., 2002).

The results of IFN- $\gamma$ assay, shown in Table 4, which was carried out on 50 tuberculin tested animals showed that the superiority of using the prepared antigen in detection of tuberculous animals over the use of tuberculin test and even the PPD-B as 25(50\%) animals were positive by IFN- $\gamma$ assay using PPD-B as a coating antigens with $96.2 \%$ sensitivity and $92.6 \%$ specificity while $22(44 \%)$ animals were positive by IFN- $\gamma$ assay using rESAT- 6 as a coating antigen with $96.6 \%$ sensitivity and $95.7 \%$ specificity.

Comparing the results of tuberculin test, IFN- $\gamma$ assay using different coating antigens and PCR as a standard method 
for diagnosis of bovine tuberculosis as shown in Table 5, it is declared that IFN- $\gamma$ assay results using rESAT- 6 was of highest specificity and sensitivity.

Importantly, whole blood testing uses minimal labor and simple equipment, allowing large numbers of samples to be tested concurrently. On the other hand, the use in a skin test could have advantages over Quanti FERON in some settings, as a skin test method may be more inexpensive and does not require a laboratory setting and trained laboratory technicians.

\section{CONCLUSIONS AND RECOMMENDATIONS}

The present study clearly demonstrates that ESAT-6 antigen could be successfully expressed and purified as recombinant proteins in a soluble form to be applicable for establishing a sensitive and specific test as an alternative to traditional diagnostic procedures. IFN- $\gamma$ and ELISA using rESAT- 6 can be used presently as a laboratory-based assay for TB diagnosis in cattle and further research has to be done before it can be used as a full-fledged field test. The results demonstrate the suitability of the preparation methods in the development of a TB diagnosis kit with potential to be diffused in high TB burden countries.

\section{NOVELTY STATEMENT}

Authors declare that the manuscript is original, has not been published before and is not currently being considered for publication elsewhere.

\section{AUTHOR'S CONTRIBUTION}

KMO and EMR planned the research and experimental design, supervised the work, checked the data analysis, and revised the manuscript. WS collected the samples, and performed the laboratory work and data analysis. $\mathrm{AH}$ helped in SDS electrophoresis, indirect ELISA and immunoblotting. All authors contributed to the drafting and revision of the manuscript. All authors read and approved the final manuscript.

\section{CONFLICT OF INTEREST}

The authors have declared no conflict of interest.

\section{REFERENCES}

-Aghazadeh R, Tebianian M, Mahdavi M (2016). Evaluation of specific Anti-ESAT-6 antibody in diagnosis of bovine tuberculosis. J. Knowledge Health, 10(4): 72-78.

-Amadori M, Tagliabue S, Lauzi S, Finazzi G, Lombardi G, Telo P,Pacciarini L, Bonizzi L (2002). Diagnosis of Mycobacterium bovis infection in calves sensitized by mycobacteria of the avium/intracellulare group, J. Vet. Med. B. Infect. Dis. Vet. Publ. Health, 49(2): 89-96.

-Arend SM, Van Meijgaarden KE, De Boer K, De Palou EC, van Soolingen D, Ottenhoff TH, van Dissel JT (2002). Tuberculin skin testing and in vitro $\mathrm{T}$ cell responses to ESAT-6 and culture filtrate protein 10 after infection with Mycobacterium marinum or $M$. kansasii. J. Infect. Dis., 186: 1797-1807.

-Behr MA, Wilson MA, Gill WP, Salamon H, Schoolnik GK, Rane S, Small PM (1999). Comparative genomics of BCG vaccines by whole-genome DNA microarray. Science, 284(5419):1520-3.

- Bennett RM, Cooke RJ (2006). Costs to farmers of a tuberculosis breakdown. Vet. Rec., 158(13):429-432.

- Berthet FX, Rasmussen PB, Rosenkrands I, Andersen P, Icquel B (1998). A Mycobacterium tuberculosis operon encoding ESAT-6 and a novel low-molecular-mass culture filtrate protein (CFP-10). Microbiology, 144(pt 11): 3195-3203.

-Brodin P, Rosenkrands I, Andersen P, Cole ST, Brosch R (2004). ESAT-6 proteins: Protective antigens and virulence factors? Trends Microbiol., 12(11): 500-508.

-Buddle BM, de Lisle GW, Pfeffer A, Aldwell FE (1995). Immunological responses and protection against Mycobacterium bovis in calves vaccinated with a low dose of BCG, Vaccine,13 (12): 1123-1130.

-Buddle BM, Wards BG, Aldwell FE, Collins DM, de Lisle GW (2002). Influence of sensitization to environmental mycobacteria on subsequent vaccination against bovine tuberculosis. Vaccine, 20: 1126-1133.

- Cosivi O, Grange JM, Daborn CJ, Raviglione MC, Fujikura T, Cousins D, Robinson RA, Huchzermeyer HF, de Kantor I, Meslin FX (1998). Zoonotic tuberculosis due to Mycobacterium bovis in developing countries. Emerg. Infect. Dis., 4: 59-70.

-Delogu G, Brennan MG (2001). Comparative immune response to PE and PE_PGRS antigens of Mycobacterium tuberculosis. Infect. Immun., 69: 5606-5611.

-Desoky SM, Essam Hatem M, Riad EM, Samir A (2015). Diagnosis of bovine tuberculosis in some Egyptian governorates with the improvement of ELISA. Egypt. J. Appl. Sci., 30 (5): 140-150.

- Dipankar D, Mavanur R, Suresh (2006). Copious production of SARS-CoV nucleocapsid protein employing codon optimized synthetic gene. J. Virol. Methods, 137(2): 343346.

-Doherty T M, Demissie A, Olobo G, Wolday D, Britton S, Eguale T, Ravn P, Andersen P (2002). Immune responses to the Mycobacterium tuberculosis-specific antigen ESAT-6 signal subclinical infection among contacts of tuberculosis patients. J. Clin. Microbiol., 40: 704-706.

-Doherty TM, Demissie A, Olobo J, Wolday D, Britton S, Eguale T, Ravn P, Andersen P (2002). Immune Responses to the Mycobacterium tuberculosis-Specific Antigen ESAT-6 Signal Subclinical Infection among Contacts of Tuberculosis Patients. J. Clin. Microbiol., 40(2): 2704-2706.

-Elhay MJ, Oettinger T, Andersen P (1998). Delayed-type hypersensitivity responses to ESAT6 and MPT64 from Mycobacterium tuberculosis in the guinea pig. Infect. Immun., 66(7): 3454-3456.

- Engvall E, Perlmann P (1972). Enzyme Linked Immunosorbent Assay (ELISA) III. Quantitative immunoglobulin antigen coating tubes. J. Immunol., 109: 129-135. 
- Farias TA, Araújo FR, Osório SLAR, Jorge KSG, Ramos CAN, Souza IIF, Azambuja A, Soares CO, Silva MR, Pellegrin AO (2012). ELISA based on recombinant MPB70 and P27 for detection of antibodies against Mycobacterium bovis. Rev. Patol. Trop., 41(2): 155-162.

- Farshadzadeh Z, Sankian M, Yousefi F, Gholobi A, Zarif R, Naderi-nasab M, Rashed T, Varasteh AR (2010). Cloning, expression and purification of early secretory antigenic target $6 \mathrm{kDa}$ protein (ESAT-6) of Mycobacterium tuberculosis, Jundishapur J. Microbiol., 3(2): 53-60.

- Hall MR, Thoen CO (1985). In vitro and in vivo evaluation of lysozyme extracts of $M$. bovis guinea pigs and calves, Am. J. Vet. Res., 46(11): 2249-2252.

- Hardie RM, Watson JM (1992). Mycobacterium bovis in England and Wales: past, present and future. Epidemiol. Infect., 109: 23-33.

- Laemmli UK (1970). Cleavage of structural protein during the assembly of the head of bacteriophage T4. Nature, 227(5259): 680- 685.

- Lauzi S, Pasotto D, Amadori M, Aechetti IL, Poli G, Bonizzi L (2000). Evaluation of the Specificity of the $\gamma$-Interferon Test in Italian Bovine Tuberculosis-free Herds. Vet. J., 160(1): 17-24.

- Lightbody KA, Skuce RA, Neill SD, Pollock JM (1998). Mycobacterial antigen-specific antibody responses in bovine tuberculosis an ELISA with potential to confirm disease status. Vet. Rec., 142: 295-300.

- Melo E, Souza I, Ramos C, Osório A, Verbisck N, Araújo F (2015). Evaluation of the use of recombinant proteins of Mycobacterium bovis as antigens in intradermal tests for diagnosis of bovine tuberculosis. Arch. Med. Vet., 47: 273280.

- Michel AL, Cooper D, Jooste J, de Klerk LM, Jolles A (2011). Approaches towards optimizing the gamma interferon assay for diagnosing Mycobacterium bovis infection in African buffalo (Synceruscaffer). Prev. Vet. Med., 98(2-3): 142-151.

-MohammadiTashakkori M, Tabatabaei M, Tebianian M, Mosavari N (2018). Production of MPT-64 recombinant protein from virulent strain of Mycobacterium bovis, IJVR. 19(2): 108-112.

- Moradi J, Mosavari N, Ebrahimi M, Arefpajohi R, Tebianian M (2015). Evaluation of Mycobacterium tuberculosis early secreted antigenic target 6 recombinant protein as a diagnostic marker in skin test, Osong Public Health Res. Perspect., 6(1): 34-38.

- Mostafavi-Pour Z, Hemmati M, Seghatoleslam A, Rasti M, Ebadat M, Mosavari N, Habibagahi M, Taheri M, Sardarian A (2011). Expression and purification of recombinant Mycobacterium tuberculosis diagnosis antigens, ESAT-6, CFP-10, and ESAT-6/CFP-10, and their potential use in the diagnosis and detection of tuberculosis, Iran. Red. Crescent Med. J., 13(8): 558-565.

-Mukherjee F (2006). Comparative prevalence of tuberculosis in two dairy herds in India. Rev. Sci. Tech., 25(3): 1125-1130.

- Nosareva O, Nesterov A, Boldyrev A, Smirnova O, Tumanov Y, Kouzmitcheva G, Tatkov S (2008). Construction of an encapsulated ESAT- 6 based anti-TB vaccine and evaluation of its immunogenic properties. Biol. Chem., 389(5): 579583.

- Okkels LM, Muller EC, Schmid M, Rosenkrands I, Kaufmann SH, Andersen P, Jungblut PR( 2004). CFP10 discriminates between nonacetylated and acetylated ESAT-6 of Mycobacterium tuberculosis by differential interaction,
Proteomics, 4(10): 2954-2960.

- Osman KM, Riad EM, Beshir WS (2017). Assessment of some mycobacterial antigens in bovine tuberculosis diagnosis, Anim. Health Res. J., 5(2): 77-88.

-Picasso-Risso C, Alvarez J, VanderWaal K, Kinsley A, Gil A, Wells SJ, Perez A (2021). Modelling the effect of testand-slaughter strategies to control bovine tuberculosis in endemic high prevalence herds. Transbound. Emerg. Dis., 68(3): 1205-1215.

-Pollock JM, Andersen P (1997). The potential of the ESAT6 antigen secreted by virulent mycobacteria for specific diagnosis of tuberculosis. J. Infect. Dis., 175: 1251-1254.

-Pollock JM, Andersen P (1997). Predominant recognition of the ESAT-6 protein in the first phase of infection with Mycobacterium bovis in cattle. Infect. Immun., 65: 25872592.

- Pollock JM, Girvin RM, Lightbody KA, Clements RA, Neill SD, Buddle BM, Andersen P (2000). Assessment of defined antigens for the diagnosis of bovine tuberculosis in skin testreactor cattle. Vet. Rec., 3;146(23):659-65.

- Pollock JM, Neill CD (2002). Mycobacterium bovis infection and tuberculosis in cattle. Vet. J., 163: 115-127.

- Sambrook J, Fritsch EF, Maniatis T (1992). Molecular cloning: A laboratory manual, $2^{\text {nd }}$ eds. pp. 880-897, Science Press, Beijing, PR China.

- Skjøt RL, Oettinger T, Rosenkrands I, Ravn P, Brock I, Jacobsen S, Andersen P (2000). Comparative evaluation of low-molecular-mass proteins from Mycobacterium tuberculosis identifies members of the ESAT-6 family as immunodominant T-cell antigens, Inf. Imm., 68(1): 214220.

-Van-Lume DS, Souza JR, Melo WG, Melo VL, Cabral M M, Rego JC, Schindler HC, Abath FG, Montenegro SM (2008). Preliminary results in the immunodiagnosis of tuberculosis in children based on $\mathrm{T}$ cell responses to ESAT6 and PPD antigens. Mem. Inst. Oswaldo. Cruz., 103(4): 401-404.

- Vordermeier HM, Chambers MA, Cockle PJ, Whelan AO, Simmons J, Hewinson RG (2002). Correlation of ESAT6-specific gamma interferon production with pathology in cattle following Mycobacterium bovis BCG vaccination against experimental bovine tuberculosis. Infect. Immun., 70(6): 3026-3032.

-Wang BL, Xu Y, Wu CQ, Xu YM, Wang HH (2005). Cloning, expression and refolding of a secretory protein ESAT- 6 of Mycobacterium tuberculosis. Prot. Exp. Purif., 39(2): 184-188.

-Wards BJ, de Lisle GW, Collins DM (2000). An ESAT6 knockout mutant of Mycobacterium bovis produced by homologous recombination will contribute to the development of a live tuberculosis vaccine. Tuber. Lung Dis., 80(4-5): 185-189.

-Waters WR, Buddle BM, Vordermeier HM, Gormley E, Palmer MV,ThackerTC,Bannantine JP,StabelJR, Linscott R, Marte E, Milian F, Foshaug W, Lawrence JC (2011). Development and evaluation of an enzyme-linked immunosorbent assay for use in the detection of bovine tuberculosis in cattle. Clin. Vaccine Immunol., 18(11): 1882-1888.

-Whelan C, Shuralev E, Kwok HF, Kenny K, Duignan A, Good M, Davis WC, Clarke J (2011). Use of a multiplex enzymelinked immunosorbent assay to detect a subpopulation of Mycobacterium bovis-infected animals deemed negative or inconclusive by the single intradermal comparative tuberculin skin test. J. Vet. Diagn. Invest., 23(3): 499-503. 
-Whelan C, Shuralev E, OKeeffe G, Hyland P, Kwok HF, Snoddy P, OBrien A, Connolly M, Quinn P, Groll M, Watterson T, Call S, Kenny K, Duignan A, Hamilton MJ, Buddle BM, Johnston JA, Davis WC, Olwill SA, Clarke J (2008). Multiplex immunoassay for serological diagnosis of Mycobacterium bovis infection in cattle. Clin. Vac. Immunol., 15: 1834-1838.

-Wobeser G (2009). Bovine tuberculosis in Canadian wildlife: an updated history. Can. Vet. J., 50(11): 1169-76.

-Wood PR, Corner LA, Plackett P (1990). Development of a simple, rapid in vitro cellular assay for bovine tuberculosis based on the production of gamma interferon. Res. Vet. Sci., 49(1): 46-49.

-Wood PR, Rothel JS (1994). In vitro immunodiagnostic assays for bovine tuberculosis. Vet. Microbiol., 40 (1-2): 125-135.

-Xu Y, Wang B, Chen J, Wang Q, Zhu B, Shen H, Qie Y, Wang J, Wang H (2006). Chimaeric protein improved immunogenicity compared with fusion protein of Ag85B and ESAT-6 antigens of Mycobacterium tuberculosis. Scand. J. Immunol., 64(5): 476-481. 